\title{
Supporting the support groups
}

\author{
Peter T Scardino
}

In the US there are over 450 disease-related patient support and advocacy groups. Many of these organizations arose as support groups, which help to counter the fear and helplessness that come with serious illness by providing emotional support, information and advice to patients and their families. A good example of a highly effective support group is UsTOO, for men with prostate cancer. A nonprofit, grassroots organization, with local chapters across the US, it is dedicated to providing education about prostate cancer and emotional support for men with cancer, and their loved ones. Founded and managed by prostate-cancer survivors, UsTOO communicates through its website and a monthly newsletter, but functions mostly by facilitating access to others who have faced the disease. Local chapters meet several times a year, creating a supportive community who share information and experiences.

Advocacy groups take a different approach. Often highly organized and professionally managed, their agenda is to influence public policy in support of research; in short, to find a cure as quickly as possible. The most effective disease-related advocacy group in the US is the National Breast Cancer Coalition (NBCC), which has assembled 70,000 activists in over 600 member organizations to advocate for breast cancer research, education and access to care. Their primary focus has been to increase governmental funding for breast cancer research, and they have been credited with increasing federal funding more than eightfold, from US $\$ 90$ million to over $\$ 800$ million by 2003. The NBCC spearheaded the National Action Plan on Breast Cancer to coordinate the efforts of government, industry, consumer groups and the scientific community. They helped ensure passage of the Breast and Cervical Cancer Treatment Act of 2000, which expanded access for women with low incomes to screening and treatment. The agenda of advocacy groups like the NBCC is clearly political. They mount letter-writing campaigns
While

sometimes

excessive

in their

zeal, these

organizations

have raised

awareness of

the impact of

disease and

advanced

the pace of

research.

PT Scardino is Editorin-Chief of Nature

Clinical Practice

Urology.

\section{Competing interests}

The author declared he has no competing interests.

www.nature.com/clinicalpractice doi:10.1038/ncpuro0401 and train advocates to lobby governmental leaders at all levels to support their cause.

Similarly, the Prostate Cancer Foundation (PCF) has been a highly effective advocacy group. Dedicated to finding a cure for advanced prostate cancer, it has raised over $\$ 250$ million to support research since 1993. Its lobbying efforts have resulted in a 20 -fold increase in governmental funding for prostate cancer research. The PCF has advanced the research agenda by sponsoring a scientific retreat each year that brings together prostate cancer physicians and scientists with leaders in cancer research, the pharmaceutical industry and government, to promote innovation and remove barriers.

For urologic diseases, there are other wellestablished groups. The Interstitial Cystitis Association and the Kidney Cancer Association combine support functions with advocacy, and the National Association for Continence emphasizes education, public awareness and support. While sometimes excessive in their zeal, these organizations have raised awareness of the impact of disease and advanced the pace of research. As the PCF advocates, additional funding for prostate cancer research does not need to come at the expense of breast cancer research, but from defense or other components of the federal budget. After all, over 500,000 people die of cancer every year in the US, while the federal budget for cancer research is less than $\$ 6$ billion out of a total budget of nearly $\$ 2,500$ billion.

The support groups mentioned above represent just a few of the many groups worldwide that provide valuable services to patients and their families; services that the medical community is not well equipped to provide. These groups bring people together to share experiences, facilitate communication, and open doors to new information. When properly used, in conjunction with professional medical advice, they can help patients make better decisions about their health care. Support groups deserve the support of urologists. 